\title{
EQ-5D-3L health state utility values in transfusion-dependent thalassemia patients in Malaysia: a cross-sectional assessment
}

\author{
Asrul Akmal Shafie ${ }^{1,2^{*}}$ (D) Irwinder Kaur Chhabra ${ }^{1,3}$ (D), Jacqueline Hui Yi Wong ${ }^{1,4}$ (B) \\ and Noor Syahireen Mohammed ${ }^{1,5}$ (B)
}

\begin{abstract}
Purpose: There is a gap of information describing the health state utility values (HSUVs) of transfusion-dependent thalassemia (TDT) patients in Malaysia. These values are useful in the assessment of health-related quality of life (HRQoL), economic evaluations and provide guidance to disease management decisions. The objective of this study was to estimate and derive HSUVs associated with the treatment and complications of TDT patients in Malaysia using the EQ-5D-3L instrument.
\end{abstract}

Methods: A cross-sectional survey using the EQ-5D-3L instrument was conducted between May to September 2018 across various public hospitals in Malaysia. Using a multi-stage sampling, patients diagnosed with TDT and receiving iron chelating therapy were sampled. The findings on the EQ-5D-3L survey were converted into utility values using local tariff values. A two-part model was used to examine and derive the HSUVs associated with the treatment and complications of iron overload in TDT.

Results: A total of 585 patients were surveyed. The unadjusted mean (SD) EQ-5D-3L utility value for TDT patients were 0.893 (0.167) while mean (SD) EQ VAS score was 81.22 (16.92). Patients who had more than two iron overload complications had a significant decline in HRQoL. Patients who were on oral monotherapy had a higher utility value of 0.9180 compared to other regimen combinations.

Conclusion: Lower EQ-5D-3L utility values were associated with patients who developed iron overload complications and were on multiple iron chelating agents. Emphasizing compliance to iron chelating therapy to prevent the development of complications is crucial in the effort to preserve the HRQoL of TDT patients.

\section{Background}

Thalassemia is the most prevalent hereditary hematologic disorder worldwide [1, 2]. Approximately $1.5 \%$ of the global population are estimated to be carriers of the $\beta$-thalassemia, with higher incidence in populations from the Mediterranean basin, Middle East, Indian

\footnotetext{
*Correspondence: aakmal@usm.my

${ }^{1}$ Discipline of Social and Administrative Pharmacy, School

of Pharmaceutical Science, Universiti Sains Malaysia, 11800 Gelugor, Pulau Pinang, Malaysia

Full list of author information is available at the end of the article
}

subcontinent, Southeast Asia, Melanesia, and the Pacific Islands [3]. In Malaysia, there is an estimated carrier rate of 3.5-4.0\% [4] and an estimated annual birth rate of 2.1/1000 [5]. As of August 2018, the Malaysian Thalassemia Registry reports that there are 7,984 thalassemia patients in the country and the numbers have increased since 2009 [6, 7]. Transfusion-dependent thalassemia (TDT) is an inherited blood disease characterized by the absence or decreased synthesis of one or more globin chains in the haemoglobin molecule, leading to chronic anaemia. Treatment for this condition involves a combination of blood transfusion to correct the anaemia, original author(s) and the source, provide a link to the Creative Commons licence, and indicate if changes were made. The images or other third party material in this article are included in the article's Creative Commons licence, unless indicated otherwise in a credit line to the material. If material is not included in the article's Creative Commons licence and your intended use is not permitted by statutory regulation or exceeds the permitted use, you will need to obtain permission directly from the copyright holder. To view a copy of this licence, visit http://creativecommons.org/licenses/by/4.0/. The Creative Commons Public Domain Dedication waiver (http://creativeco mmons.org/publicdomain/zero/1.0/) applies to the data made available in this article, unless otherwise stated in a credit line to the data. 
followed by iron chelating therapy to remove the excess iron resulting from the transfusion [8]. The thalassemia's are likely to remain a global health problem in the future. There has been major efforts to better prevention and management of the disease [9].

The diagnosis of TDT has shown to affect a patient's health-related quality of life (HRQoL) [10] and should be considered as an important index when evaluating treatment outcomes as it can be used to inform patient management and policy decisions [11]. Several studies have been conducted in Malaysia to assess the HRQoL of TDT patients between 2006 to 2013. Most of these studies utilized instruments such as the PedsQL 4.0 Generic Core Scales (GCS) [12-14] and Medical Outcomes Study Short Form 36-item (MOS SF-36) [15]. They showed that the diagnosis of TDT negatively impacts the HRQoL of patients. Patients undergo physical changes such as the development of thalassemia facies and stunted growth. The recurrent blood transfusion increases their risk of developing iron overload complications such as cardiac complications and diabetes, adding on to the disease burden [8]. The long-term use of medications, frequent hospital visits and fatigue brought about by the chronic anaemia disrupts their ability to function and can cause emotional distress [16]. However, these studies have been limited to the paediatric and adolescent TDT population. Apart from that, the HRQoL instruments used were nonpreference-based instruments. Although these instruments quantify a health state in terms of functioning and symptoms, its scores are not weighted neither is there 'value' attached to it, making it difficult to use the outcomes in economic evaluations.

Value is measured in terms of 'preference' for a health state [17]. Health state utility values (HSUVs) represents an individual's preference for being in a health state and can be measured indirectly using preference-based health-related quality of life instruments such as the EQ-5D. These utility values allow for meaningful comparison across different diseases and they are an important component of economic evaluations. The EQ-5D instrument was developed by the EuroQol Group and it consists of a descriptive system and a visual analogue scale (EQ VAS) [18]. The descriptive system has five dimensions (mobility, self-care, usual activities, pain/discomfort, anxiety/depression), each with either a 3-level response level (EQ-5D-3L) or a 5-level response level (EQ-5D-5L). A child-friendly version (EQ-5D-Y) has also been developed with a simpler language, suitable for use in children and adolescents. The responses on the descriptive system is used to form a unique health state which is subsequently converted into a single index value or a health state utility value (HSUV). The index value ranges from a score of 1 (referring to full health) and 0 (referring to a state as bad as being dead) or it may also take on negative values, representing health states considered to be worse than dead. These values are obtained from a standardized valuation exercise obtained from the general population in a country. This ensures that the values represent the societal perspective [18]. The 3L version of the instrument generates 243 possible health states whereas the $5 \mathrm{~L}$ version generates 3125 possible health states. In Malaysia, both the 3L [19] and 5L [20] value sets are available, whereas the EQ-5D-Y value set is not yet available. In the second part of the instrument, the EQ VAS, respondents would indicate how they felt about their health on the day the survey was being performed. The EQ VAS is presented on a vertical health thermometer with 0 being the worst health imaginable, and 100 being the best health imaginable [18].

As of date, there is no study that describes the HSUV for the transfusion-dependent thalassemia population in the country. Thus, the objective of this study was to survey the HSUVs and health profiles of both paediatric and adult transfusion-dependent thalassemia (TDT) patients in Malaysia using the EQ-5D-3L instrument. The availability of a validated Malay version of the questionnaire and a country-specific general population tariff in Malaysia makes the use of the EQ-5D-3L instrument ideal. In addition to that, this study aims to derive HSUVs based on the iron chelating agent regimen used and the various iron overload complications associated with the condition. These HSUVs would be key drivers in cost effectiveness analyses as estimates of quality-adjusted life years (QALYs) are obtained by multiplying these utility values with the time spent in the health state.

\section{Methods}

\section{Study design and participant recruitment}

This cross-sectional study was conducted between May to September 2018 in Malaysia. Participants were selected using multi-stage sampling. In the first stage, Malaysia was divided into five regions based on its geographical location. In the second stage, a non-probability sampling was used to sample patients from each region. Tertiary referral hospitals which provide dedicated care for thalassemia patients were identified in each region and patients were recruited from these centres.

The sample size was determined using the population prevalence formula. Based on a population 7,984 [6], $5 \%$ precision rate, $95 \%$ confidence level and an assumption [21] of $50 \%$ disease prevalence, an estimated sample of at least 367 should be recruited. Recruitment criteria includes patients aged three years and above, a diagnosis of transfusion-dependent thalassemia, has received treatment of iron chelating therapy for at least six months and a proficiency in English or the Malay language to 
complete the surveys. Patients who defaulted treatment or regular follow up for at least a year, have impaired cognitive function, a diagnosis of non-transfusion dependent thalassemia or other hemoglobinopathies were excluded from this study.

\section{Data collection}

One month prior to data collection, a nationwide training of interviewers was conducted to ensure consistency of data collection. Interviewers were given a set of forms consisting of a patient information sheet, informed consent forms for participation, parental consent form, age appropriate assent forms, EQ-5D-3L instrument and data collection form capturing patient's sociodemographic data, and medical history. Both the Malay and English language version of the EQ-5D-3L instruments were used in this study. The instrument was previously validated in Malaysia [22] and a local value set is available [19]. Study coordinators visited study sites to randomly validate the data collection forms with the medical records to ensure accuracy of the collected data before the end of the data collection period.

Patients were screened and selected by the trained interviewers when they came in for routine follow up based on the inclusion and exclusion criteria. Prior to the face-to-face interview, both the patients and parents (if proxy-reported) were briefed about the objective of the study and assured that information collected would remain confidential. Informed consents and the child's assent were obtained upon agreement to participate. Parents or caregivers were requested to answer the questionnaires on behalf of children aged between 3 and 12 years of age, as young children may not have the ability to decipher and respond to the questions. Adolescents above 12 years old were given the choice to self-report their own quality of life or if they could not, a parent proxyreport was done. Patients aged 18 years and above were expected to self-report their quality of life.

This study was registered with the National Medical Research Register (NMRR) of Malaysia (NMRR-17-261438966) and was approved by the Medical Research and Ethics Committee (MREC).

\section{Statistical analysis}

Statistical analysis was conducted using STATA version 14 [23]. Descriptive statistical analysis including sum, percentage, mean and standard deviation was used to describe the sociodemographic, clinical factors, EQ-5D-3L domain responses, index and EQ VAS of the patients. The frequency and percentage of health profiles formed from the domain responses of the sample were also summarized. The EQ-5D-3L health profiles were then scored using the Malaysian EQ-5D-3L tariff set derived from a time-trade off multiplicative model $[19,24]$. The distribution of EQ-5D-3L responses were summarized based on the population (pediatric or adult) and the source of the survey (self-reported or proxyreported). Statistical significance of any reported problems between these groups would be examined using a Chi-square test. To summarize the responses of the EQ$5 \mathrm{D}-3 \mathrm{~L}$ domains, the response was aggregated into 'no reported problems' and 'reported problems' by combining the response of 'some problems' and 'extreme problems'. Statistical significance of the responses between the various demographic factors of patients would be examined using a Chi-square test.

The data normality of the EQ-5D-3L index and the EQ VAS was determined by observing the histogram and conducting a Shapiro-Wilk test. Depending on the normality data outcomes, statistical significance of differences between unadjusted means of the utility values and EQVAS scores would be tested (unpaired t-test or ANOVA if parametric and Mann-Whitney $U$ test or Kruskal-Wallis test if non parametric). In addition to that, the calculation of effect sizes which measures the magnitude of the difference between the groups were performed. Cohen's $d$ measures the effect size by converting the difference between the means of two groups into standard deviation units (mean group 1 - means group $2 /$ standard deviation). Values of (0.2-0.5), (0.5-0.8) and $(>0.8)$ corresponds to small, moderate and large differences in HRQoL [25].

The utility values are expected to be skewed, whereby many patients would report perfect health, as illustrated and discussed in previous studies [26, 27]. In this study, a two-part model was used to examine the association between the various groups of transfusion-dependent thalassemia patients and the disutility score (i.e. 1-EQ5D-3L utility value) $[27,28]$. The two-part model, which was estimated using STATAs twopm command, consists of two parts-a logistic regression and a generalized linear model [29]. The logistic regression first models the probability of disutility. The second part of the model utilized a generalized linear model with a gamma distribution and a log link function, as it showed the best fit based on comparisons of Akaike Information Criteria from various models. The analyses were adjusted for sociodemographic factors (age, gender, ethnicity, education level), number of iron overload complications, the specific coexisting complications, and the iron chelating therapy regimen. The analysis was conducted using the full sample $(n=585)$ and a restricted sample $(n=429)$. In the restricted sample, patients who reported perfect health but had iron overload complications were excluded from the analysis. Marginal effects (decrements of utility scores) based on the change in the demographic 
and treatment factors were estimated using STATAs margins command using the full sample.

Results were considered statistically significant for $p<0.05$ in all the analysis.

\section{Results}

The sociodemographic and clinical characteristics of the 585 patients sampled are described in Table 1 . There were more females $(55.7 \%)$ than male $(44.3 \%)$ patients. The mean (SD) age of the sample was 17.2 (5.4) years, with an age range between 3 and 60 years old. Majority of the samples were of the Malay ethnicity. Since young children were also recruited for this study, the source of the HRQoL may have been self-reported (56.8\%) or proxyreported (43.2\%). In both the self-reported and proxy reported groups, majority of the patients had received a primary or secondary education with $71.7 \%$ and $62.5 \%$ respectively. The mean (SD) age of initiating blood transfusion was 5.4 (7.9) years old while the mean (SD) number of transfusion years was 11.3 (8.9). A total of $56.6 \%$ of patients had no iron overload complications while the remaining $43.4 \%$ of patients reported the presence of at least one complication. Out of those who reported complications, $48.8 \%$ reported complications related to the liver. Majority of the patients were on monotherapy treatment (66.0\%). The oral route of administration (56.6\%) was the most common route of administration. Only $13.0 \%$ of the sampled population had any history of a serious adverse event with iron chelating therapy.

Out of the 243 possible health profiles with the EQ5D-3L, 32 health profiles were reported, with $67.35 \%$ of patients reporting a health state of 11,111 , followed by $10.09 \%$ reporting a health state of 11,121 (Additional file 1: Table 1). Figure 1 summarizes the distribution of health profiles for the sampled population. The pain/ discomfort (20.2\%) and the anxiety/depression (13.5\%) domain had a higher percentage of reported problems compared to the other domains. Table 2 summarizes the distribution of EQ-5D-3L responses based on the population and source of survey. Based on the paediatric and adult population, the difference in score was significant on the mobility and self-care domains, with the pediatric population reporting more problems on the self-care domain while the adult population reported more problems on the mobility domain. Based on the source of the survey, there was a significant difference in the mobility, self-care and anxiety/depression domain. Respondents who self-reported reported more problems on the mobility and anxiety/depression domain whereas proxyreported respondents reported more problems on the self-care domain.

A summary of the domain responses by sociodemographic and clinical factors based on aggregates of "no problem reported" and "problem reported" are shown in Additional file 1: Table 2. Using a Chi-square test, the aggregated domain responses were tested for statistical significance. Factors taken into consideration were gender, the presence of iron overload complications, the route and number of iron chelating (ICT) agents and the history of serious adverse events (SAE) with ICT use. On the mobility domain, all 5 factors were statistically significant whereas none of these factors were significant in the self-care domain. On the usual activity domain, the presence of iron overload complications, route, the number of iron chelating agents used and history of SAE were significant. On the pain/discomfort domain, only the presence of iron overload complications was significant. On the anxiety/depression domain, gender, presence of iron overload complications and the number of iron chelating agents used was significant.

Based on the number of iron overload complications, Fig. 2 illustrates the distribution of EQ-5D-3L utility values. Populations without iron overload complications tend to have a higher index score compared to populations with an IOL complication. The range of utility scores in the sample was limited between 0.4454 and 1.000 .

The unadjusted mean (SD) EQ-5D-3L utility value for the entire sample was $0.893(0.167)$ while the mean (SD) EQ VAS score was 81.22 (16.92), as summarized in Table 3. Based on the EQ-5D-3L utility values, statistical significance from Mann-Whitney and Kruskal-Wallis test found the variables of gender (effect size $=0.202$ ), the presence of iron overload (effect size $=0.257$ ), route of iron chelating therapy (effect size $=0.215$ for oral and 0.06 for combination therapy compared to subcutaneous) and the number of iron chelating agents used (effect size $=0.274)$ to be statistically significant. However, the effect sizes of these variables were only small, with a coefficient that ranged less than 0.5 , with the number of chelating agents used having the largest effect size.

Based on the EQ VAS, the Mann-Whitney and Kruskal-Wallis test found the source of survey (effect size $=0.439$ ), category of child or adult (effect size $=0.611$ ), the presence of iron overload (effect size $=0.288$ ), route of iron chelating therapy (effect size $=0.347$ for oral and 0.047 for combination therapy compared to subcutaneous) and the number of iron chelating agents used (effect size $=0.299$ ) to be statistically significant. The effect size of the child or adult category was the largest with a value of 0.611 .

Table 4 presents the HSUVs for the different types of iron chelating agents and specific iron overload complications which were generated using a two-part model, controlling for gender and the presence of iron overload complications in the model. The analysis 
Table 1 Patients sociodemographic and clinical characteristics

\begin{tabular}{|c|c|}
\hline Characteristics & Total $(N=585)$ \\
\hline Age in years, mean (SD) & $17.2(5.4)$ \\
\hline Age at first transfusion in years, mean (SD) & $5.4(7.9)$ \\
\hline Number of years receiving blood transfusion, mean (SD) & $11.3(8.9)$ \\
\hline \multicolumn{2}{|l|}{ Source of survey (\%) } \\
\hline Self-reported & $332(56.8)$ \\
\hline Proxy-reported & $253(43.2)$ \\
\hline \multicolumn{2}{|l|}{ Gender (\%) } \\
\hline Male & $259(44.3)$ \\
\hline Female & $326(55.7)$ \\
\hline \multicolumn{2}{|l|}{ Ethnicity (\%) } \\
\hline Malay & $403(68.9)$ \\
\hline Chinese & $94(16.1)$ \\
\hline Kadazan-Dusun & $58(9.9)$ \\
\hline Others & $30(5.1)$ \\
\hline \multicolumn{2}{|c|}{ Education level of proxy's who completed proxy-report, $n=251(\%)$} \\
\hline No formal education & $10(4.0)$ \\
\hline Primary or secondary education & $180(71.7)$ \\
\hline Tertiary education & $61(24.3)$ \\
\hline \multicolumn{2}{|c|}{ Education level of patients who completed self-report, $n=331(\%)$} \\
\hline No formal education & $3(0.9)$ \\
\hline Primary or secondary education & $207(62.5)$ \\
\hline Tertiary education & $121(36.6)$ \\
\hline \multicolumn{2}{|l|}{ Presence of iron overload (IOL) complication (\%) } \\
\hline No complication & $331(56.6)$ \\
\hline One complication & $164(28.0)$ \\
\hline Two complications & $66(11.3)$ \\
\hline Three or more complications & $24(4.1)$ \\
\hline Cardiac disease & $39\left(15.3^{*}\right)$ \\
\hline Diabetes & $20\left(7.9^{*}\right)$ \\
\hline Hypothyroid & $25\left(9.8^{*}\right)$ \\
\hline Hypogonadism & $90\left(35.4^{*}\right)$ \\
\hline Hypoparathyroidism & $52\left(20.5^{*}\right)$ \\
\hline Liver disease & $124\left(48.8^{*}\right)$ \\
\hline \multicolumn{2}{|l|}{ Iron chelation therapy (\%) } \\
\hline Desferrioxamine (subcutaneous (SC) drug) & $68(11.6)$ \\
\hline Deferasirox (oral (PO) drug) & $245(41.9)$ \\
\hline Deferiprone (oral (PO) drug) & $73(12.5)$ \\
\hline Desferrioxamine + Deferiprone (SC + PO drug) & $154(26.3)$ \\
\hline Desferrioxamine + Deferasirox (SC + PO drug) & $32(5.8)$ \\
\hline Deferiprone + Deferasirox (both oral drugs) & $13(2.2)$ \\
\hline \multicolumn{2}{|l|}{ Number of iron chelating agents (\%) } \\
\hline Monotherapy & $386(66.0)$ \\
\hline Dual therapy & $199(34.0)$ \\
\hline \multicolumn{2}{|l|}{ Route of iron chelating administration (\%) } \\
\hline Subcutaneous & $68(11.6)$ \\
\hline Oral & $331(56.6)$ \\
\hline Subcutaneous + Oral & $186(31.8)$ \\
\hline \multicolumn{2}{|l|}{ History of serious adverse event with iron chelation therapy (\%) } \\
\hline Yes & $76(13.0)$ \\
\hline No & $509(87.0)$ \\
\hline
\end{tabular}

$\mathrm{N}$, number; SD, standard deviation; IOL, iron overload complication; SC, subcutaneous; PO, oral

* Percentage calculated based on the total number of people who has complication 


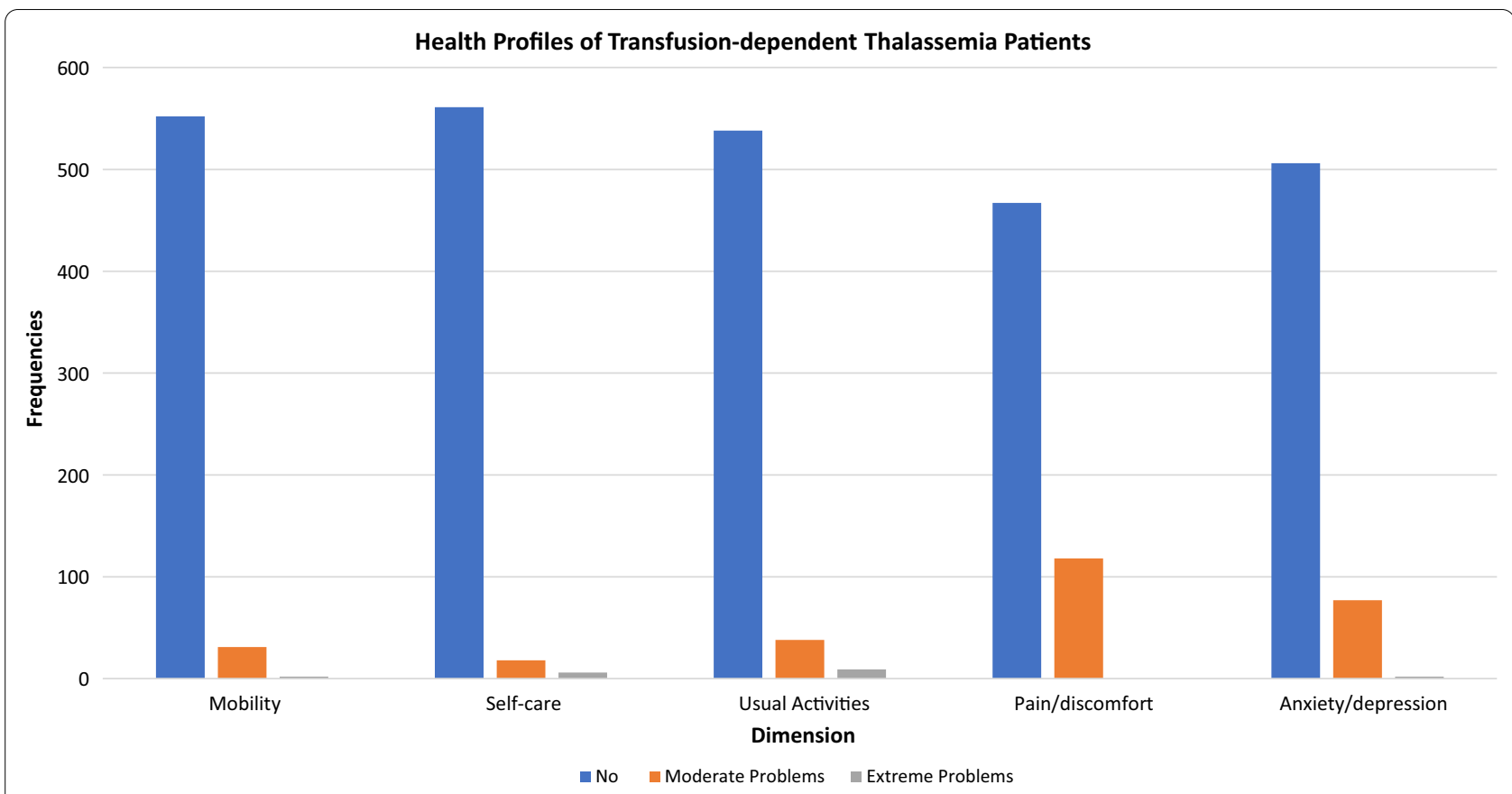

Fig. 1 Health profiles of transfusion-dependent thalassemia patients

was conducted using the full sample $(\mathrm{n}=585)$ and a restricted sample $(n=429)$. In the restricted sample, patients who reported perfect health but had iron overload complications were excluded from the analysis. We hypothesized that patients who had iron overload complications would not be able to achieve perfect health and hence wanted to examine what the HSUVs would be without that cohort. Using the full sample, patients who had diabetes had the lowest utility value of 0.815 compared to other iron overload complications. However, when the restricted sample was used, patients with hypothyroid had the lowest utility value of 0.838 . In both sample analysis, patients who were on oral monotherapy had a higher utility value compared to other routes of administration. Based on the full sample, the health state utility values using a subcutaneous iron chelator (0.893) resulted in a utility decrement of $2.7 \%$ compared to when an oral iron chelator $(0.918)$ is used, whereas patients in the restricted sample had a utility decrement of $17.9 \%$. In addition to the route of administration, the number of iron chelators used can affect the HRQoL of patients, whereby patients who had more than one iron chelator had lower utility values compared to those who had monotherapy in both the samples.

The marginal effects of the various sociodemographic and clinical factors on the disutility score were analysed using STATA's two-part model margins command on the full sample (Additional file 1: Table 3). Gender, length of transfusion, presence of iron overload complications and number of iron chelating agents used were found to be significant predictors for the disutility score. When comparing the EQ-5D-3L utility values of patients with complications to patients without complications in the two-part model, the HRQoL declining effect becomes significant when there are at least two coexisting complications. Patients who used dual iron chelating agents had lower utility scores by 0.15 points when compared to those who were on monotherapy.

\section{Discussion}

As of date, there are no studies that has surveyed the health state utility values (HSUV) of transfusion-dependent thalassemia (TDT) patients in Malaysia and this study aims to fill that gap. The availability of these values would aid policy makers in the decision-making process related to disease management for these group of patients, especially since TDT is a chronic and expensive disease.

A ceiling effect was seen in the sample with $67.35 \%$ of patients reporting perfect health and this may be attributed to the EQ-5D-3L instrument used. Although the EQ-5D-5L instrument has been shown to be superior compared to the EQ-5D-3L [30], the EQ-5D-3L instrument was chosen because of studies which support the validity of its use in children [31-33] in the absence of the EQ-5D-Y value sets, since both the pediatric and adult population was sampled. In addition to that, a 3-level response would be simpler to administer compared to a 5-level response. 
Table 2 Distribution of EQ-5D-3L responses by population and source of survey

\begin{tabular}{|c|c|c|c|c|c|c|}
\hline \multirow[t]{2}{*}{ Dimension } & \multicolumn{3}{|c|}{ By population category } & \multicolumn{3}{|l|}{ By source of survey } \\
\hline & Pediatric $(n=364)$ & $\begin{array}{l}\text { Adult } \\
(n=221)\end{array}$ & $p$ value & Self-report $(n=332)$ & $\begin{array}{l}\text { Proxy-report } \\
(n=253)\end{array}$ & $p$ value \\
\hline \multicolumn{7}{|l|}{ Mobility } \\
\hline Level 1 & $351(96.4)$ & $201(91.0)$ & & $306(92.2)$ & $246(97.2)$ & \\
\hline Level 2 & $11(3.0)$ & $20(9.1)$ & & $25(7.5)$ & $6(2.4)$ & \\
\hline Level 3 & $2(0.6)$ & $0(0)$ & & $1(0.3)$ & $1(0.4)$ & \\
\hline Any problem in mobility (\%) & $13(3.6)$ & $20(9.1)$ & $0.005^{*}$ & $26(7.8)$ & $7(2.8)$ & $0.009^{*}$ \\
\hline \multicolumn{7}{|l|}{ Self-care } \\
\hline Level 1 & $344(94.5)$ & $217(98.2)$ & & $325(97.9)$ & $236(93.3)$ & \\
\hline Level 2 & $14(3.9)$ & $4(1.8)$ & & $7(2.1)$ & $11(4.4)$ & \\
\hline Level 3 & $6(1.7)$ & $0(0)$ & & $0(0)$ & $6(2.4)$ & \\
\hline Any problem in self-care (\%) & $20(5.5)$ & $4(1.8)$ & $0.029^{*}$ & $7(2.1)$ & $17(6.7)$ & $0.005^{*}$ \\
\hline \multicolumn{7}{|l|}{ Usual activities } \\
\hline Level 1 & $338(92.9)$ & $200(90.5)$ & & $306(92.2)$ & $232(91.7)$ & \\
\hline Level 2 & $20(5.5)$ & $18(8.1)$ & & $23(6.9)$ & $15(5.9)$ & \\
\hline Level 3 & $6(1.7)$ & $3(1.4)$ & & $3(0.9)$ & $6(2.4)$ & \\
\hline Any problem in usual activity (\%) & $26(7.1)$ & $21(9.5)$ & 0.309 & $26(7.8)$ & $21(8.3)$ & 0.836 \\
\hline \multicolumn{7}{|l|}{ Pain/discomfort } \\
\hline Level 1 & $297(81.6)$ & $170(76.9)$ & & $260(78.3)$ & $207(81.8)$ & \\
\hline Level 2 & $67(18.4)$ & $51(23.1)$ & & $72(21.7)$ & $46(18.2)$ & \\
\hline Level 3 & $0(0)$ & $0(0)$ & & $0(0)$ & $0(0)$ & \\
\hline Any problem in pain/discomfort (\%) & $67(18.4)$ & $51(23.1)$ & 0.172 & $72(21.7)$ & $46(18.2)$ & 0.295 \\
\hline \multicolumn{7}{|l|}{ Anxiety/depression } \\
\hline Level 1 & $321(88.2)$ & $185(83.7)$ & & $278(83.7)$ & $228(90.1)$ & \\
\hline Level 2 & $41(11.3)$ & $36(16.3)$ & & $53(16.0)$ & $24(9.5)$ & \\
\hline Level 3 & $2(0.6)$ & $0(0)$ & & $1(0.3)$ & $1(0.4)$ & \\
\hline Any problem in anxiety/depression (\%) & $43(11.8)$ & $36(16.3)$ & 0.125 & $54(16.3)$ & $25(9.9)$ & $0.025^{*}$ \\
\hline
\end{tabular}

Values of scores are presented as $\mathrm{n}(\%)$, number (percentage)

$p$ value using Chi-square test

*indicates significance at $p$ value $<0.05$

This study found differences between the domain responses of pediatric and adult patients. The lower number of reported problems on the self-care domain of older patients may be explained by the independence and knowledge that the patient gains over the years when coping with the condition [13,34]. Pediatric patients also tend to be more dependent on their caregivers for daily tasks, hence explaining the higher number of reported problems on the self-care domain. As patients grew older, the burden of treatment may increase with higher volume of blood required, onset of complications and the need for higher dosages of iron chelating therapy, possibly contributing to the higher number of reported problems on the mobility and anxiety/depression domain, although the difference was only significant in the mobility domain. Respondents who self-reported reported higher number of problems in the mobility and anxiety/depression domain. This is expected as they would be able to perceive better a limitation in their daily routine. Respondents who proxy-reported reported a higher number of problems on the self-care domain, as caregivers are the one who would be helping patients in their self-care routine, and would be less able to perceive the other domains which may not be observed physically such as pain/discomfort and anxiety/depression.

The mean (SD) HSUV of 0.893 (0.167) in this study was slightly higher than the HSUVs surveyed among TDT patients using iron chelating therapy in Iran. The study, which utilized US and Iran's time trade-off value set, had a HSUV range of 0.81 to 0.86 [35]. A similar trend was also observed on the EQ VAS scale, where our patients had a mean (SD) score of 81.22 (19.92) compared to a score of 72.9 (1.1) in Iran [35]. The utility value range between 0.8 to 0.9 had no reported frequencies as the plausible range on the Malaysian EQ-5D-3L tariff set had 


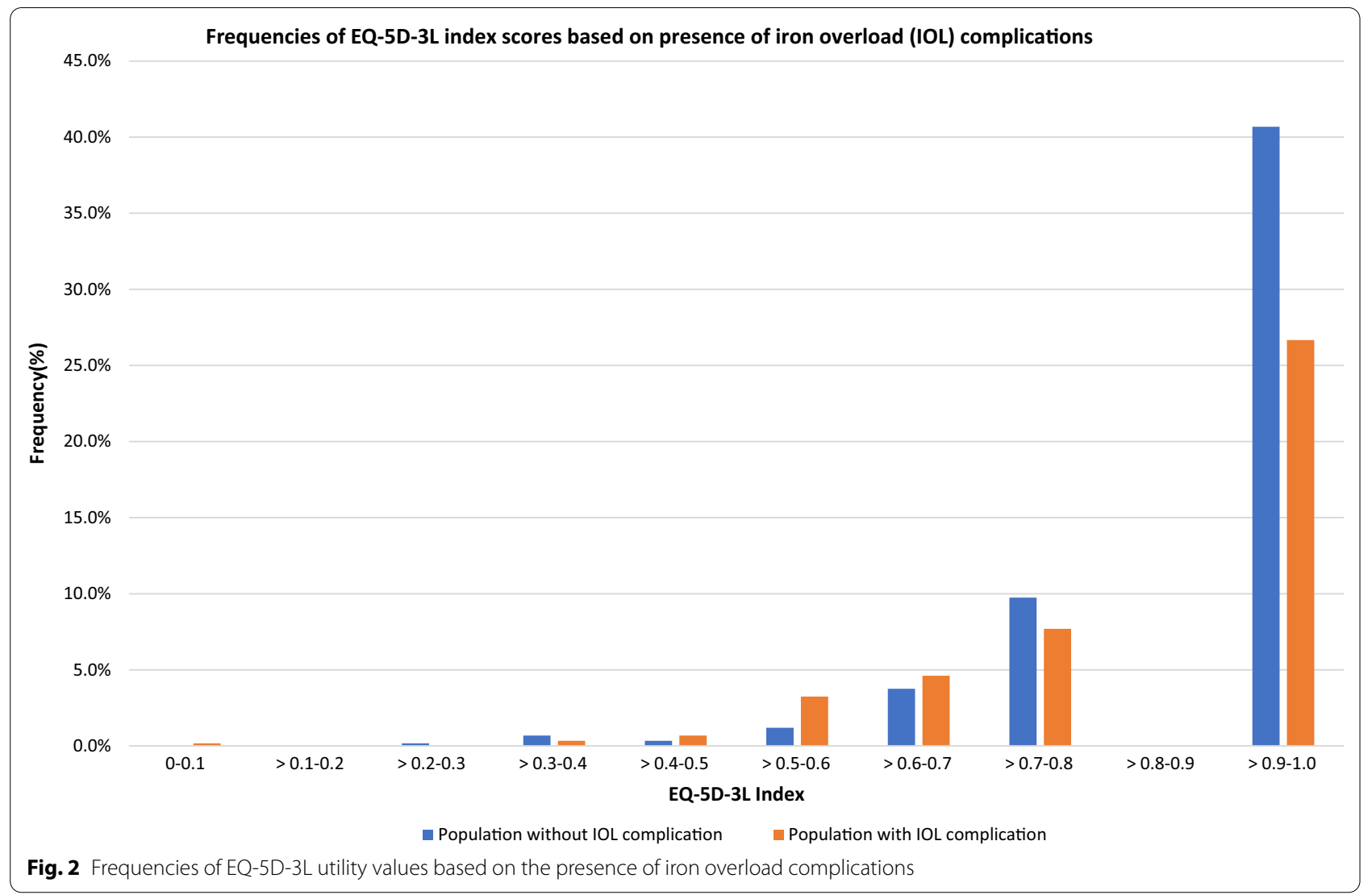

a gap between the health state 11,111 (utility value $=1.00$ ) and 11,112 (utility value $=0.756$ ) [19].

The distribution of utility values sampled were skewed, with many patients reporting perfect health and this was also evident in previous studies [26, 27]. The skewed distribution violates ordinary least squares (OLS) regression assumptions. Hence, a two-part model (TPM) was used to derive the HSUVs, controlling for age, the type of iron overload and type of iron chelator. In the two-part model, the disutility score (i.e. 1-EQ-5D-3L utility value) [27, 28 ] was used to predict the HRQoL scores based on the variables. The two-part model is useful for models with mixed discrete continuous outcomes. In this study, the first part of the two-part model predicts the probability of obtaining a disutility score of 0 (perfect health), followed by the second part of the model that predicts the disutility score using a generalized linear model (GLM) [29]. The GLM model was chosen as it allows the outcome variable to be a link function of the linear index of the covariates instead of the outcome variable simply being a linear function of the covariates. This also avoids the problem of retransformation inherent in models that transformed the outcome variable to meet OLS assumptions [36].
Based on the full and restricted sample, the health state utility values using a subcutaneous iron chelator resulted in a utility decrement of $2.7 \%$ and $17.9 \%$ compared to when an oral iron chelator is used. The study conducted in Iran showed a decrement of $6.9 \%$ when using a subcutaneous iron chelator or combination therapy compared to an oral chelator or a monotherapy [35]. Although these findings of decrement are consistent with previous studies, the utility decrement in this study and the study conducted in Iran is much smaller compared to a time trade-off study conducted in Australia [37] and the United Kingdom [38] that investigated the utility associated with the use of oral and subcutaneous iron chelating therapy. In both studies, a decrement of $28.2 \%$ and $21.4 \%$ respectively occurred when using a subcutaneous ICT compared to the oral ICT. However, it should be noted that these two studies utilized a direct elicitation valuation method with respondents from the community, while the current study and the study in Iran utilized a generic preference-based instrument with TDT patient. This highlights the effect of different valuation methods and respondents in eliciting HSUVs.

Amongst the various iron overload complications, cardiac and diabetes complications result in the highest disutility of $8.2 \%$ and $8.4 \%$ (full sample) or $6.5 \%$ 
Table 3 Summary of EQ-5D-3L mean utility values (unadjusted) and EQ VAS

\begin{tabular}{|c|c|c|c|c|c|c|c|c|}
\hline \multirow[t]{2}{*}{ Factors } & \multicolumn{4}{|c|}{ EQ-5D-3L utility values } & \multicolumn{4}{|l|}{ EQ VAS } \\
\hline & Mean (SD) & Median (IQR) & $p$ value $e^{\pi}$ & Effect size & Mean (SD) & Median (IQR) & $p$ value ${ }^{\pi}$ & Effect size \\
\hline Total sample & $0.893(0.167)$ & $1.000(0.269)$ & - & - & $81.22(16.92)$ & $85.00(25.00)$ & - & - \\
\hline \multicolumn{9}{|l|}{ Source of survey } \\
\hline Self-reported & $0.887(0.165)$ & $1.000(0.269)$ & 0.219 & 0.080 & $78.08(18.19)$ & $80.00(20.00)$ & $<0.001^{*}$ & 0.439 \\
\hline Proxy-reported & $0.900(0.169)$ & $1.000(0.255)$ & & & $85.36(14.10)$ & $90.00(15.00)$ & & \\
\hline \multicolumn{9}{|l|}{ Gender } \\
\hline Male & $0.911(0.157)$ & $1.000(0.244)$ & $0.011^{*}$ & 0.202 & $82.29(15.53)$ & $85.00(20.00)$ & 0.450 & 0.114 \\
\hline Female & $0.878(0.173)$ & $1.000(0.269)$ & & & $80.37(17.93)$ & $85.00(25.00)$ & & \\
\hline \multicolumn{9}{|l|}{ Category } \\
\hline Child ( $\leq 18$ years old) & $0.898(0.163)$ & $1.000(0.255)$ & 0.079 & 0.371 & $84.97(15.16)$ & $90.00(15.00)$ & $<0.001^{*}$ & 0.611 \\
\hline Adult & $0.884(0.172)$ & $1.000(0.269)$ & & & $75.04(17.86)$ & $80.00(25.00)$ & & \\
\hline \multicolumn{9}{|l|}{$\begin{array}{l}\text { Presence of iron overload } \\
\text { complication }\end{array}$} \\
\hline Absent & $0.911(0.153)$ & $1.000(0.244)$ & $0.002^{*}$ & 0.257 & $83.31(16.61)$ & $85.00(15.00)$ & $<0.001^{*}$ & 0.288 \\
\hline Present & $0.869(0.180)$ & $1.000(0.269)$ & & & $78.49(16.70)$ & $80.00(20.00)$ & & \\
\hline \multicolumn{9}{|l|}{$\begin{array}{l}\text { Route of iron chelating } \\
\text { therapy }\end{array}$} \\
\hline Subcutaneous (SC) only & $0.877(0.187)$ & $1.000(0.269)$ & $0.016^{¥, *}$ & Reference Group & 78.45 (15.68) & $80.00(20.00)$ & $<0.001^{¥, *}$ & Reference Group \\
\hline Oral (PO) only & $0.911(0.151)$ & $1.000(0.244)$ & & 0.215 & $83.82(15.41)$ & $90.00(15.00)$ & & 0.347 \\
\hline $\mathrm{SC}+\mathrm{PO}$ & $0.866(0.181)$ & $1.000(0.269)$ & & 0.060 & 77.60 (19.06) & $80.00(20.00)$ & & 0.047 \\
\hline \multicolumn{9}{|l|}{$\begin{array}{l}\text { Number of iron chelating } \\
\text { agents }\end{array}$} \\
\hline Monotherapy & $0.908(0.153)$ & $1.000(0.255)$ & $0.005^{*}$ & 0.274 & $82.95(15.52)$ & $87.50(20.00)$ & $<0.001^{*}$ & 0.299 \\
\hline Dual therapy & $0.863(0.186)$ & $1.000(0.269)$ & & & 77.90 (18.95) & $80.00(20.00)$ & & \\
\hline \multicolumn{9}{|l|}{$\begin{array}{l}\text { History of serious adverse } \\
\text { event with iron chelating } \\
\text { therapy }\end{array}$} \\
\hline Yes & $0.881(0.181)$ & $1.000(0.269)$ & 0.585 & 0.078 & $78.16(17.52)$ & $85.00(20.00)$ & 0.068 & 0.208 \\
\hline No & $0.894(0.164)$ & $1.000(0.269)$ & & & 81.67 (16.80) & $80.00(20.00)$ & & \\
\hline
\end{tabular}

and $7.3 \%$ (restricted sample) respectively compared to respondents without complications. These values were higher compared to the study conducted in Iran which had a disutility of $3.6 \%$ (cardiac) and $6.0 \%$ (diabetes) when compared to patients who did not have the complication [35]. A cost-utility analysis conducted in the United States used the assumption that TDT patients with cardiac disease would have a $15 \%$ decrement in utility [39] based on TTO values for heart failure as reported in a longitudinal cohort study of health status and HRQoL [40]. These findings imply that the prevention of iron overload complications is crucial in preserving the HRQoL of patients. Based on the marginal effects, as with other chronic conditions [41], this study showed that the presence of coexisting comorbidities in TDT is associated with a lower HRQoL. The decrease in HRQoL becomes statistically significant when the number of complications exceeds two. Compliance to iron chelation therapy is essential in the prevention of the development of iron overload complications. Apart from the increased risk of morbidity and mortality, poor compliance to iron chelating therapy has also shown to increase the cost of treating the disease [42]. The choice of iron chelators has been highlighted as a determinant of HRQoL in TDT patients [43-45] and the findings of this study further emphasizes the preference for oral iron chelation.

This study has a few limitations. First, it was not compared to a healthy general population, hence making it difficult to truly estimate the impact of the disease on the HRQoL. In addition, due to time constraints and the variation in documentation of medical records across centres, it was a challenge to obtain additional clinical parameters which could have been used to assess the severity of the disease such as the serum ferritin levels. As is common for 
Table 4 Health state utility values derived from the two-part model

\begin{tabular}{|c|c|c|c|c|c|c|}
\hline \multirow[t]{2}{*}{ Health state } & \multicolumn{3}{|c|}{ Full sample $(n=585)$} & \multicolumn{3}{|c|}{ Restricted sample $(n=429)$} \\
\hline & Utility value & $95 \% \mathrm{Cl}$ & & Utility value & $95 \% \mathrm{Cl}$ & \\
\hline $\begin{array}{l}\text { TDT with non-specific iron overload com- } \\
\text { plication }\end{array}$ & 0.852 & 0.811 & 0.893 & 0.905 & 0.880 & 0.929 \\
\hline TDT with cardiac complication & 0.820 & 0.742 & 0.897 & 0.846 & 0.805 & 0.887 \\
\hline TDT with diabetes & 0.815 & 0.711 & 0.919 & 0.839 & 0.788 & 0.890 \\
\hline TDT with hypothyroid & 0.853 & 0.761 & 0.945 & 0.838 & 0.787 & 0.889 \\
\hline TDT with hypogonadism & 0.841 & 0.785 & 0.896 & 0.860 & 0.827 & 0.893 \\
\hline TDT with hypoparathyroidism & 0.894 & 0.832 & 0.955 & 0.856 & 0.815 & 0.897 \\
\hline TDT with liver iron overload & 0.826 & 0.778 & 0.875 & 0.929 & 0.907 & 0.951 \\
\hline TDT with desferrioxamine (DFO) & 0.893 & 0.880 & 0.906 & 0.779 & 0.707 & 0.852 \\
\hline TDT with deferasirox (DFX) & 0.915 & 0.856 & 0.974 & 0.854 & 0.837 & 0.870 \\
\hline TDT with deferiprone (DFP) & 0.940 & 0.875 & 1.005 & 0.778 & 0.698 & 0.859 \\
\hline TDT with DFO + DFP & 0.903 & 0.841 & 0.964 & 0.749 & 0.691 & 0.808 \\
\hline TDT with DFO + DFX & 0.862 & 0.229 & 0.953 & 0.758 & 0.662 & 0.854 \\
\hline TDT with DFX + DFP & 0.814 & 0.653 & 0.975 & 0.754 & 0.591 & 0.917 \\
\hline TDT on subcutaneous (SC) therapy & 0.893 & 0.879 & 0.906 & 0.779 & 0.706 & 0.852 \\
\hline TDT on oral (PO) therapy & 0.918 & 0.860 & 0.976 & 0.949 & 0.902 & 0.997 \\
\hline TDT on SC + PO therapy & 0.895 & 0.834 & 0.957 & 0.890 & 0.837 & 0.942 \\
\hline
\end{tabular}

$\mathrm{Cl}$, confidence interval; TDT, transfusion-dependent thalassemia; DFO, desferrioxamine; DFX, deferasirox; DFP, deferiprone; SC, subcutaneous; $\mathrm{PO}$, oral

quality of life data, the results were skewed in a way that higher scores were reported more than lower scores. A ceiling effect was also seen in our results $(67.35 \%$ reported perfect health) indicating that a complete variation in health states were not fully captured. The use of EQ-5D-3L in children also presents methodological concerns such as the relevance of the domains, appropriateness of the instrument based on the cognitive ability and the concordance between self and proxy reports. Agreement between the self-report and proxy-report was also not examined as respondents were only surveyed once. Unfortunately, the absence of other suitable utility tariffs in the country, the evidence that support the validity of EQ-5D-3L use in children [31-33] and the simple administration of the EQ$5 \mathrm{D}-3 \mathrm{~L}$ instrument made it attractive for use. Finally, based on a literature search, the minimum clinically importance difference (MCID) which represents the smallest amount of benefit that the patient can recognize and value has not been defined for TDT. This limits our ability to compare the actual impact of using different treatment regimens and route of administrations on the HRQoL and to assess if patients have significantly improved, declined or remained stable [46]. Further empirical work is required in this area.

\section{Conclusion}

In this study, the HRQoL of TDT patients in Malaysia were surveyed using the EQ-5D-3L instrument and converted into utility values using a Malaysian specific tariff.
The mean (SD) EQ-5D-3L utility value for TDT patients were $0.893(0.167)$ while the mean (SD) EQ VAS score was 81.22 (16.92). The reduction of HRQoL becomes more prominent when there are at least two coexisting complications. These findings emphasize the importance of preventing the development of iron overload complications. However, the prevention of iron overload is heavily dependent on a patient's compliance to their iron chelating therapy. The availability of these values would be useful for clinicians, researchers and policy makers in the decision-making process for disease management.

\section{Supplementary Information}

The online version contains supplementary material available at https://doi. org/10.1186/s12955-020-01645-0.

Additional file 1. Frequencies of health profiles reported.

\section{Acknowledgements}

The authors would like to thank the Director General of the Ministry of Health Malaysia for the permission to publish the research findings of this study. The authors would like to thank the paediatricians, interviewers (Faizah binti Mohd Hanapiah, Mohd Hafizudin bin Mohd Salim, Mohamad Khudri bin Khairudin, Siti Nur Syahida binti Abdul Jalil, Muhammad Farid bin Abdul Ghaffar, Nur Liyana binti Kamaronzaman, Mohd Saharudin bin Mat Salim, Nurul Syafika binti Mohd Hairi, Analisa Coldelia Anak Rumpu, Elvyshirah Hadirin, Raphaela Romanus, Nur Asyilla Aslinda binti Mohd Nasir, Nurzuliana bint Hassim, Mohd Afiq bin Mohs Azis, Hamizah Kharber, Nur Athirah binti Abdul Razak, Nor Afifa Mazlan, Mohd Afiq bin Mohd Sulaiman, Nurain Syahirah binti Abu Bakar), patients, parents and caregivers from the various hospitals in Malaysia for participating and their cooperation in making this study possible. 


\section{Authors' contributions}

AAS was involved in the revision of the paper for intellectual content and in the design, interpretation, analysis of data and proofreading the manuscript. IKC was involved in the drafting of the manuscript, analysis and interpretation of the data. JWHY was involved in the design, collection, training, validation of the study and data and proofreading the manuscript. NSM was involved in the training, validation of the study and data and proofreading the manuscript. All authors read and approved the final manuscript.

\section{Funding}

No financial support was received for this study.

\section{Availability of data and materials}

The datasets used and/or analysed during the current study are available from the corresponding author on reasonable request.

\section{Ethics approval and consent to participate}

This study was registered with the Malaysian National Medical Research Registry (NMRR -17-2614-38966). This study was also approved by the Malaysian Research and Ethics Committee. Prior to each interview, written consents and assents were obtained from both caregivers and patients who were willing to participate.

\section{Consent for publication}

Not applicable.

\section{Competing interests}

The authors declare that they have no competing interests.

\section{Author details}

1 Discipline of Social and Administrative Pharmacy, School of Pharmaceutical Science, Universiti Sains Malaysia, 11800 Gelugor, Pulau Pinang, Malaysia. ${ }^{2}$ Institutional Planning and Strategic Centre, Universiti Sains Malaysia, 11800 Gelugor, Pulau Pinang, Malaysia. ${ }^{3}$ Pharmacy Department, Sabah Women and Children's Hospital, Ministry of Health Malaysia, Karung Berkunci No.187, 88996 Kota Kinabalu, Sabah, Malaysia. ${ }^{4}$ Pharmacy Department, Hospital Kuala Lumpur, Ministry of Health Malaysia, Jalan Pahang, 50586 Kuala Lumpur, Wilayah Persekutuan Kuala Lumpur, Malaysia. ${ }^{5}$ Clinical Research Center, Hospital Sultanah Bahiyah, Ministry of Health Malaysia, KM 6, Jalan Langgar, 05460 Alor Setar, Kedah Darul Aman, Malaysia.

Received: 29 July 2020 Accepted: 9 December 2020

Published online: 07 January 2021

\section{References}

1. Rund D, Rachmilewitz E. ß-Thalassemia. N Engl J Med. 2005:353:1135-46.

2. Weatherall D, Clegg J. Historical perspectives: in The Thalassemia syndromes. 4th ed. Oxford UK: Blackwell Scientific; 2001.

3. De Sanctis V, Kattamis C, Canatan D, et al. $\beta$-thalassemia distribution in the old world: an ancient disease seen from a historical standpoint. Mediterr J Hematol Infect Dis. 2017:9:e2017018.

4. Elizabeth G, Ann TM. Genotype-phenotype diversity of beta-thalassemia in Malaysia: treatment options and emerging therapies. Med J Malaysia. 2010;65:256-60

5. George E. Beta-thalassemia major in Malaysia, an ongoing public health problem. Med J Malaysia. 2001;56(4):397-400.

6. Ibrahim MH. Malaysian Thalassaemia Registry Report. 1st ed. Medical Development Division, Ministry of Health Malaysia. 2019

7. Ibrahim HM, Hassan A, George E, Goh Al, et al. Management of Transfusion Dependent Thalassaemia. In: Health Technology Assessment Section MDD. Putrajaya: CPG Secretariat; 2009, p. 1-21.

8. Cappellini M-D, Cohen A, Porter J, Taher A, Viprakasit V. Guidelines for the management of transfusion dependent thalassaemia (TDT). Cyprus: Thalassaemia International Federation Nicosia; 2014

9. Weatherall DJ. The evolving spectrum of the epidemiology of thalassemia. Hematol Oncol Clin. 2018:32:165-75.

10. Telfer P, Constantinidou G, Andreou P, Christou S, Modell B, Angastiniotis M. Quality of life in thalassemia. Ann N Y Acad Sci. 2005:1054:273-82.
11. Guyatt GH, Feeny DH, Patrick DL. Measuring health-related quality of life. Ann Intern Med. 1993;118:622-9.

12. Ismail A, Campbell MJ, Ibrahim HM, Jones GL. Health related quality of life in Malaysian children with thalassaemia. Health Qual Life Outcomes. 2006;4:39.

13. Sazlina S, Asauji Y, Juni MH. Predictors of health related quality of life among children and adolescents with beta thalassemia in three hospitals in Malaysia: a cross sectional study. Int J Public Health Clin Sci. 2015:2:1-12.

14. Ismail M, Chun CY, Shahar S, et al. Quality of life among thalassaemia children, adolescent and their caregivers. Sains Malaysiana. 2013;42:373-80.

15. Dahlui M, Hishamshah MI, Rahman A, Aljunid SM. Quality of life in transfusion-dependent thalassaemia patients on desferrioxamine treatment. Singapore Med J. 2009;50:794.

16. Suzanah A, Zulaiha M, Faszrul AA, Kamaruzaman W. Thalassaemia: a study on the perception of patients and family members. Med J Malaysia. 2011;66:327.

17. Karimi M, Brazier J. Health, health-related quality of life, and quality of life: what is the difference? Pharmacoeconomics. 2016;34:645-9.

18. Foundation ER. EQ-5D-3L User Guide. 2018.

19. Shafie AA, Thakumar AV. Multiplicative modelling of EQ-5D-3L TTO and VAS values. Eur J Health Econ. 2020;21:1411-20.

20. Shafie AA, Vasan Thakumar A, Lim CJ, Luo N, Rand-Hendriksen K, Md Yusof FA. EQ-5D-5L valuation for the malaysian population. Pharmacoeconomics. 2019:37:715-25.

21. Naing L, Winn T, Rusli B. Practical issues in calculating the sample size for prevalence studies. Arch Orofac Sci. 2006:1:9-14.

22. Shafie AA, Hassali MA, Liau SY. A cross-sectional validation study of EQ-5D among the Malaysian adult population. Qual Life Res. 2011;20:593-600.

23. StataCorp. Stata statistical software: release 14. College Station, TX: StataCorp LP.2015.

24. Shafie AA, Thakumar AV. Multiplicative modelling of EQ-5D-3L TTO and VAS values. Eur J Health Econ. 2020;21(9):1411-20.

25. Sullivan GM, Feinn R. Using effect size-or why the $P$ value is not enough J Grad Med Educ. 2012;4:279-82.

26. Huang IC, Frangakis C, Atkinson MJ, et al. Addressing ceiling effects in health status measures: a comparison of techniques applied to measures for people with HIV disease. Health Serv Res. 2008:43:327-39.

27. Li L, Fu AZ. Some methodological issues with the analysis of preference-based EQ-5D index score. Health Serv Outcomes Res Method. 2009;9:162-76.

28. Jalkanen $\mathrm{K}$, Aarnio $\mathrm{E}$, Lavikainen $\mathrm{P}$, Jauhonen $\mathrm{H}-\mathrm{M}$, Enlund $\mathrm{H}$, Martikainen J. Impact of type 2 diabetes treated with non-insulin medication and number of diabetes-coexisting diseases on EQ-5D-5 L index scores in the Finnish population. Health Qual Life Outcomes. 2019;17:117.

29. Belotti F, Deb P, Manning WG, Norton EC. twopm: Two-part models. Stata J. 2015:15:3-20.

30. Janssen MF, Bonsel GJ, Luo N. Is EQ-5D-5L better than EQ-5D-3L? A headto-head comparison of descriptive systems and value sets from seven countries. Pharmacoeconomics. 2018;36:675-97.

31. Vitale MG, Levy DE, Johnson MG, et al. Assessment of quality of life in adolescent patients with orthopaedic problems: are adult measures appropriate? J Pediatr Orthop. 2001:21:622-8.

32. Noyes J, Edwards R. EQ-5D for the assessment of health-related quality of life and resource allocation in children: a systematic methodological review. Value Health. 2011;14:1117-29.

33. Brussoni M, Kruse S, Walker K. Validity and reliability of the EQ-5D-3L ${ }^{\mathrm{TM}}$ among a paediatric injury population. Health Qual of Life Outcomes. 2013;11:157.

34. Thavorncharoensap M, Torcharus K, Nuchprayoon I, Riewpaiboon A Indaratna K, Ubol B-O. Factors affecting health-related quality of life in Thai children with thalassemia. BMC Hematol. 2010;10:1.

35. Seyedifar M, Dorkoosh FA, Hamidieh AA, et al. Health-related quality of life and health utility values in beta thalassemia major patients receiving different types of iron chelators in Iran. Int J Hematol Oncol Stem Cell Res. 2016;10:224-31.

36. Deb P, Norton EC, Manning WG. Health econometrics using Stata. College Station: Stata Press; 2017

37. Osborne RH, Lourenço RDA, Dalton A, et al. Quality of life related to oral versus subcutaneous iron chelation: a time trade-off study. Value Health. 2007:10:451-6. 
38. Karnon J, Tolley K, Oyee J, Jewitt K, Ossa D, Akehurst R. Cost-utility analysis of deferasirox compared to standard therapy with desferrioxamine for patients requiring iron chelation therapy in the United Kingdom. Curr Med Res Opin. 2008;24:1609-21.

39. Delea TE, Sofrygin O, Thomas SK, Baladi J-F, Phatak PD, Coates TD. Cost effectiveness of once-daily oral chelation therapy with deferasirox versus infusional deferoxamine in transfusion-dependent thalassaemia patients. Pharmacoeconomics. 2007;25:329-42.

40. Fryback DG, Dasbach EJ, Klein R, et al. The Beaver Dam Health Outcomes Study: initial catalog of health-state quality factors. Med Decis Making. 1993;13:89-102.

41. Lubetkin El, Jia H, Franks P, Gold MR. Relationship among sociodemographic factors, clinical conditions, and health-related quality of life: examining the EQ-5D in the US general population. Qual Life Res. 2005; 14:2187-96.

42. Delea TE, Edelsberg J, Sofrygin O, et al. Consequences and costs of noncompliance with iron chelation therapy in patients with transfusiondependent thalassemia: a literature review. Transfusion. 2007:47:1919-29.

43. Abetz $L$, Baladi J-F, Jones P, Rofail D. The impact of iron overload and its treatment on quality of life: results from a literature review. Health Qual Life Outcomes. 2006;4:73.
44. Porter J, Bowden DK, Economou M, et al. Health-related quality of life, treatment satisfaction, adherence and persistence in $\beta$-thalassemia and myelodysplastic syndrome patients with iron overload receiving deferasirox: results from the EPIC clinical trial. Anemia. 2012;2012:297641.

45. Scalone L, Mantovani LG, Krol M, et al. Costs, quality of life, treatment satisfaction and compliance in patients with $\beta$-thalassemia major undergoing iron chelation therapy: the ITHACA study. Curr Med Res Opin. 2008;24:1905-17.

46. Jaeschke R, Singer J, Guyatt GH. Measurement of health status: ascertaining the minimal clinically important difference. Control Clin Trials. 1989;10:407-15.

\section{Publisher's Note}

Springer Nature remains neutral with regard to jurisdictional claims in published maps and institutional affiliations.
Ready to submit your research? Choose BMC and benefit from:

- fast, convenient online submission

- thorough peer review by experienced researchers in your field

- rapid publication on acceptance

- support for research data, including large and complex data types

- gold Open Access which fosters wider collaboration and increased citations

- maximum visibility for your research: over $100 \mathrm{M}$ website views per year

At BMC, research is always in progress.

Learn more biomedcentral.com/submissions 